\title{
Avaliação de Impacto Ambiental: Uma Revisão Sistemática sob a Ótica Metodológica
}

\section{Environmental Impact Assessment: A Systematic Review under the Methodological Perspective}

\author{
1Thamires Silva Martins, ${ }^{2}$ Gersina Nobre da Rocha Carmo Junior \\ ${ }^{1}$ Engenheira Sanitarista e Ambiental e Mestranda do Programa de Pós-Graduação em Engenharia de Edificações \\ e Ambiental da Faculdade de Arquitetura, Engenharia e Tecnologia, Universidade Federal de Mato Grosso, Av. \\ Fernando Corrêa da Costa, 2367, FAET, Cuiabá-MT(thamiresmartinsms@ outlook.com) \\ ${ }^{2}$ Doutora em Engenharia Ambiental, Professora Adjunto IV da Faculdade de Arquitetura, Engenharia e \\ Tecnologia,Universidade Federal de Mato Grosso, Av. Fernando Corrêa da Costa, 2367, FAET, Cuiabá-
}

MT(gersina@ufmt.br)

\begin{abstract}
RESUMO: A constatação dos efeitos, em geral negativos, causados ao meio ambiente por meio de atividades antrópicas, colaborou de maneira enfática na criação de normas e condições básicas para que um empreendimento possa se apoderar de uma área em determinado espaço, evitando significativas alterações ao meio ambiente. Nesta conjuntura, desenvolveram-se os métodos de Avaliação de Impacto Ambiental (AIA), que fazem predições dos efeitos de um determinado empreendimento a curto, médio e longo prazo. Desta forma, o presente trabalho tem por objetivo geral identificar as principais metodologias utilizadas na avaliação de impactos ambientais. Como objetivos específicos tem-se: abordar as potencialidades e limitações das metodologias e reconhecer a metodologia mais empregada na AIA de empreendimentos rodoviários, tendo em vista a grande dificuldade encontrada na identificação dos impactos desta categoria. O referencial metodológico adotado é a revisão sistemática, empregando uma janela temporal de 15 anos e descritores em língua portuguesa e inglesa. Os resultados mostram que as principais metodologias empregadas nos processos de AIA são: Ad Hoc, Listas de Controle, Matrizes de Interação, Redes de Interações, Superposição de Mapas e Modelos de Simulação, sendo a Matriz de Interação a mais utilizada em avaliações de impactos em rodovias. As informações técnicas sobre cada um dos métodos disponíveis podem auxiliar profissionais da área de AIA na escolha ou na fusão destes, visando que sejam compatíveis com a natureza do empreendimento ou fator causador de alterações ambientais que se deseja estudar, tendo em vista que não há um método específico compatível com todos os tipos de projeto.
\end{abstract}

Palavras-chave: AIA. Gestão ambiental. Licenciamento ambiental. Meio ambiente. Rodovia.

ABSTRACT: The negative environmental effects caused by anthropic activities have forcefully contributed to the creation of norms and basic conditions so that an enterprise can take over an area in a certain space, avoiding significant changes to the environment. In this context, Environmental Impact Assessment (EIA) methods have been developed, which construct predictions of the effects of a given enterprise in the short, medium and long term. Thus, the present study has the general objective to identify the main methodologies used in the evaluation of environmental impacts. The specific objectives are: to address the potentialities and limitations of the methodologies and recognize the most applied EIA methodology in road projects, given the great difficulty found in identifying impacts in this category. The methodological framework adopted herein was a systematic review, using a 15-year window and descriptors in Portuguese and English. The results indicate that the main methodologies employed in the EIA processes are: Ad Hoc, Control Lists, Interaction Matrices, Interaction Networks, Overlay Mapping and Simulation Models. The Interaction Matrix is the most applied in highway impact assessments. The technical information on each of the available methods can assist EIA practitioners in EIA selection or merging in order to be compatible with the nature of the undertaking or as a causal factor of environmental change to be evaluated, since no specific method is compatible with all project types.

Keywords: EIA. Environmental management. Environmental licensing. Environment. Highway.

\section{INTRODUÇÃO}

O termo Avaliação de Impacto Ambiental (AIA) foi relatado pela primeira vez a partir dos estudos desenvolvidos nos Estados Unidos da América (EUA), com a publicação da National Environmental PolicyAct - NEPA (Lei da Política Nacional do Meio Ambiente) no ano de 1970. Seguindo-se a esta, inúmeros estudos foram desenvolvidos no continente 
Europeu em função da evolução dos problemas que tangem o desenvolvimento econômico desassociado da proteção ao meio ambiente (MILARÉ, 2011).

No Brasil, o primeiro procedimento jurídico referente à AIA foi a Lei de Zoneamento Industrial nas Áreas Críticas de Poluição, que consiste da Lei Federal n. ${ }^{\circ}$ 6.803/80 (BRASIL 1980). No ano seguinte, com a criação da Lei Federal n. ${ }^{\circ} 6.938 / 1981$ que aborda sobre a Política Nacional do Meio Ambiente, foi instituído em seu Art. $9^{\circ}$ inciso III, a avaliação de impacto ambiental como instrumento de gestão pública ambiental no Brasil (BRASIL, 1981).

Ainda na década de 80, foi publicada a Resolução n. ${ }^{\circ}$ 001/1986 do Conselho Nacional do Meio Ambiente (CONAMA), que dispõe sobre os critérios básicos e diretrizes gerais para a AIA (BRASIL, 1986). A referida resolução define impactos ambientais como "qualquer alteração das propriedades físicas, químicas e biológicas no meio ambiente, causada por qualquer forma de matéria ou energia resultante das atividades humanas que, direta ou indiretamente, afetam a saúde, a segurança e o bem-estar da população; as atividades sociais e econômicas; a biota; as condições estéticas e sanitárias do meio ambiente; a qualidade dos recursos ambientais".

A posteriori, em 1992, na Conferência da Organização das Nações Unidas sobre Meio Ambiente e Desenvolvimento realizada no estado do Rio de Janeiro, comumente conhecida como ECO-92 ou Rio-92, a Avaliação de Impacto Ambiental passou a ser considerada como um princípio ambiental consubstanciado em tratados internacionais (Princípio 17 da Declaração da ECO-92), estabelecendo que a AIA é um instrumento nacional para promover atividades planejadas de caráter ambiental, econômico e social, que possa acarretar em impactos negativos sobre o meio ambiente (SANTOS, 2013).

As técnicas ou métodos empregados na avaliação dos impactos ambientais tem como objetivo identificar, avaliar e sintetizar os efeitos de um determinado programa ou projeto nas áreas de influência ambiental de um determinado empreendimento. Ao proporcionar o conhecimento preliminar, a discussão e o diagnóstico imparcial dos impactos positivos e negativos de uma determinada proposta, as avaliações possibilitam evitar e mitigar os prejuízos e potencializar os benefícios, beneficiando a eficácia das soluções. Ao possibilitar o alcance da qualidade dos dados, e ao autorizar a divulgação destes, a AIA promove a diminuição dos impasses existentes entre os diferentes grupos sociais envolvidos. Deste modo, a AIA não consiste em um instrumento de decisão, mas em um instrumento que fornece subsídios ao processo de tomada de decisão (PIMENTEL; PIRES, 1992)

$\mathrm{Na}$ atualidade, existem diferentes métodos empregados nas AIA que dão suporte aos profissionais da área na identificação dos impactos e suas respectivas causas. Em suma, não há nenhum método que tenha aplicabilidade em todos os casos, tendo em vista que cada empreendimento e seu entorno possuem suas singularidades. A escolha da metodologia a ser utilizada caso a caso irá depender de inúmeros fatores, tais como: a disponibilidade de dados, as exigências legais referentes aos termos de referência, recursos técnicos e financeiros, prazos e peculiaridades dos empreendimentos (MORAES; D’AQUINO, 2016).

Não obstante, observa-se que os projetos rodoviários se destacam por terem uma área de influência maior se comparada com os demais meios de transporte e/ou empreendimentos passíveis de AIA no geral (SIMONETTI, 2010). A flexibilidade de deslocamento promovida por uma rodovia amplia notoriamente a área de influência dos impactos, sendo necessário adotar metodologias que sejam capazes de identificar impactos oriundos de grandes áreas, para fornecer subsídios na proposição de medidas mitigadoras para o referido empreendimento.

Com base no acima exposto, o objetivo desse artigo é identificar as principais metodologias utilizadas na avaliação de impactos ambientais. Os objetivos específicos são: a) identificar as principais potencialidades e limitações das metodologias encontradas e b) 
apontar a metodologia mais adequada na avaliação de impactos ambientais em empreendimentos rodoviários.

A importância deste artigo de revisão se respalda na crescente necessidade do conhecimento acerca das metodologias empregadas nos processos de AIA, para que a escolha do método adequado aplicado a um empreendimento seja capaz garantir a eficiência na avaliação. E em consequência do crescimento exponencial dos empreendimentos rodoviários no Brasil, garantir que um estudo de impacto ambiental seja realizado de maneira apropriada, fará com que os impactos recorrentes neste tipo de projeto sejam elencados integralmente, contribuindo de maneira enfática nas medidas de prevenção, mitigação e compensação futuramente propostas.

\section{MATERIAIS E MÉTODOS}

A revisão sistemática consiste em uma revisão planejada para responder a uma pergunta específica, utilizando métodos explícitos e sistemáticos para identificar, selecionar e avaliar de forma crítica os estudos, coletando e analisando os dados oriundos dos estudos existentes na revisão (CASTRO, 2001). Sampaio e Mancini (2007) afirmam que esse tipo de estudo resulta em um resumo das evidências concatenadas a uma estratégia de intervenção específica, por intermédio da aplicação de métodos explícitos e sistematizados de busca, apreciação crítica e síntese da informação selecionada. As revisões sistemáticas são, sobretudo, de grande valia para promover a integração de informações de estudos realizados de forma separada sobre determinada terapêutica/intervenção, que podem apresentar resultados conflitantes e/ou coincidentes, bem como apontar temáticas que necessitam de evidência, contribuindo na orientação para indagações futuras. Isto posto, propõe-se responder o seguinte questionamento que consiste em: Quais as metodologias de avaliações de impactos ambientais mais usuais, e, identificar qual(is) a(s) metodologia(s) mais adotadas nas avaliações de impactos oriundos de empreendimentos rodoviários?

Para o desenvolvimento desta revisão sistemática, utilizou-se como fonte de dados artigos científicos, dissertações e teses oriundos da base de dados disponíveis nos sites da CAPES, Science Direct, Scielo, Environmental Impact Assessment Review, Google Acadêmico, além do repositório das seguintes universidades: Universidade de São Paulo (USP), Instituto de Pesquisas Tecnológicas do estado de São Paulo (IPT), Universidade Federal do Rio de Janeiro (UFRJ), Universidade Federal Fluminense (UFF), Universidade Federal de Santa Catarina (UFSC) e Universidade Federal do Rio Grande do Sul (UFRGS). Conforme metodologia exposta por Moraes e D'Aquino (2016), a busca acerca do tema baseou-se em dois procedimentos de revisão sistemática distintos: Primeiramente, delineou-se uma busca sobre o tema AIA (Avaliação de Impactos Ambientais), utilizando a expressão "Avaliaç* Impacto* Ambienta*", tendo em vista que esta é a expressão mais utilizada e difundida na literatura acerca do referido assunto, não descartando expressões como "Impacto Ambient*" e "AIA". A posteriori, realizou-se uma busca acerca dos métodos mais usuais de AIA, empregando descritores como "Metodologia" AND "Avaliaç* Impacto* Ambienta*", "Método" AND "Avaliaç* Impacto* Ambienta*"e seus respectivos sinônimos, além dos termos "Rodovia" AND "Avaliaç* Impacto* Ambienta*" e "Rodovia" AND "Métod* Avaliaç* Impacto* Ambienta*", objetivando encontrar trabalhos que abordassem os empreendimentos rodoviários. Os descritores utilizados foram empregados tanto em português, quanto em inglês.

No processo de revisão sistemática, após a seleção dos estudos que versassem o tema exposto, foram aplicados critérios para avaliação da qualidade destes, adotando como base a metodologia exposta por Dresch, Lacerda e Antunes Júnior (2014), no qual são consideradas 
três dimensões para pré-avaliação. Desta forma, a Tabela 1 elucida quais são as dimensões e critérios utilizados para avaliar a qualidade dos estudos utilizados na revisão sistemática.

Tabela 1 - Critérios para avaliação das dimensões da qualidade dos estudos utilizados na revisão sistemática

\begin{tabular}{|c|c|c|c|}
\hline \multicolumn{4}{|c|}{ Dimensão } \\
\hline & Qualidade da execução do estudo & $\begin{array}{c}\text { Adequação à questão } \\
\text { da revisão }\end{array}$ & $\begin{array}{c}\text { Adequação ao foco da } \\
\text { revisão }\end{array}$ \\
\hline$\frac{\pi}{2}$ & $\begin{array}{l}\text { O método proposto atende aos padrões } \\
\text { demandados para o tema em estudo ou } \\
\text { estudo seguiu rigorosamente o método } \\
\text { proposto e os resultados se respaldam em } \\
\text { fatos e dados. }\end{array}$ & $\begin{array}{l}\text { O trabalho abrange o } \\
\text { objeto de estudo da } \\
\text { revisão sistemática. }\end{array}$ & $\begin{array}{c}\text { O trabalho foi } \\
\text { desenvolvido em } \\
\text { circunstâncias idênticas } \\
\text { às definidas para a } \\
\text { revisão }\end{array}$ \\
\hline 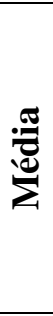 & $\begin{array}{l}\text { O método proposto apresenta lacunas em } \\
\text { relação aos padrões demandados para o } \\
\text { tema em estudo ou o estudo não } \\
\text { demonstra ter seguido o método proposto } \\
\text { em sua totalidade. }\end{array}$ & $\begin{array}{l}\text { O trabalho abrange de } \\
\text { forma parcial o objeto } \\
\text { de estudo da revisão } \\
\text { sistemática. }\end{array}$ & $\begin{array}{c}\text { O trabalho foi } \\
\text { desenvolvido } \\
\text { desenvolveu em } \\
\text { circunstâncias } \\
\text { parcialmente similares } \\
\text { às definidas para a } \\
\text { revisão. }\end{array}$ \\
\hline$\stackrel{\mathscr{x}}{\mathscr{x}}$ & $\begin{array}{l}\text { O método proposto apresenta } \\
\text { inconformidades em relação aos padrões } \\
\text { demandados para o tema em estudo ou o } \\
\text { estudo não obedeceu ao método proposto. }\end{array}$ & $\begin{array}{l}\text { O trabalho aborda de } \\
\text { forma superficial o } \\
\text { objeto de estudo da } \\
\text { revisão sistemática }\end{array}$ & $\begin{array}{c}\text { O trabalho foi } \\
\text { desenvolvido em } \\
\text { circunstâncias distintas } \\
\text { das definidas para a } \\
\text { revisão }\end{array}$ \\
\hline
\end{tabular}

Fonte: Adaptado de Dresch, Lacerda e Antunes Júnior (2014).

Após efetuar individualmente a análise dos trabalhos pré-selecionados para compor a revisão sistemática, as avaliações precisam ser consolidadas de forma a fornecer um conceito final que elucide a qualidade final dos respectivos trabalhos (DRESCH; LACERDA; ANTUNES JÚNIOR, 2014). Desta forma, adotou-se como critério de inclusão na revisão sistemática os trabalhos que apresentassem avaliação alta no critério de ponderação da qualidade (Tabela 2). Concomitantemente, adotou-se um critério temporal de 15 anos para delimitação dos estudos pesquisados. Isto posto, a Tabela 2 elucida critérios de pós-avaliação adotados na presente revisão sistemática.

Tabela 2 - Critérios de pós-avaliação

\begin{tabular}{|c|c|c|c|}
\hline \multicolumn{3}{|c|}{ Avaliação do objeto selecionado quanto à } & \multirow{2}{*}{$\begin{array}{c}\text { Critério de ponderação } \\
\text { da qualidade }\end{array}$} \\
\hline $\begin{array}{c}\text { Qualidade da } \\
\text { execução }\end{array}$ & $\begin{array}{c}\text { Adequação à questão } \\
\text { da revisão }\end{array}$ & $\begin{array}{c}\text { Adequação ao foco da } \\
\text { revisão }\end{array}$ & \\
\hline Alta & Alta & Alta & Alta \\
\hline Média & Alta & Alta & Alta \\
\hline Alta & Média & Média & Média \\
\hline Média & Alta & Média & Média \\
\hline Média & Média & Alta & Média \\
\hline Média & Média & Média & Média \\
\hline Alta & Alta & Baixa & Média \\
\hline Alta & Média & Baixa & Baixa \\
\hline Média & Média & Baixa & Média \\
\hline Média & Baixa & Baixa & Baixa \\
\hline Baixa & Baixa & Baixa & Baixa \\
\hline
\end{tabular}

Fonte: Adaptado de Dresch, Lacerda e Antunes Júnior (2014). 
MARTINS, THAMIRES; CARMO JUNIOR, GERSINA; Avaliação de Impacto Ambiental: Uma Revisão Sistemática sob a Ótica Metodológica.E\&SEngineeringand Science, (2018), 7:2.

\section{RESULTADOS/DISCUSSÕES}

Foram pré-selecionados 26 trabalhos e após a aplicação dos critérios de pós-avaliação (Quadro 1), foram selecionados quinze trabalhos com avaliação alta para compor a revisão sistemática.

Quadro 1 - Estudos pré-selecionados e critérios de pós-avaliação da qualidade

\begin{tabular}{|c|c|c|c|c|c|c|c|}
\hline \multirow[b]{2}{*}{ Referência } & \multirow[b]{2}{*}{ Ano } & \multirow[b]{2}{*}{ Tipo } & \multirow[b]{2}{*}{ Idioma } & \multicolumn{3}{|c|}{ Pré-Avaliação } & \multirow[b]{2}{*}{$\begin{array}{c}\text { Pós- } \\
\text { Avaliação }\end{array}$} \\
\hline & & & & $\begin{array}{l}\text { Qualidade } \\
\text { da } \\
\text { Execução }\end{array}$ & $\begin{array}{l}\text { Adequação } \\
\text { à questão } \\
\text { da revisão }\end{array}$ & $\begin{array}{c}\text { Adequação } \\
\text { ao foco da } \\
\text { revisão }\end{array}$ & \\
\hline $\begin{array}{l}\text { Macêdo et } \\
\text { al. }\end{array}$ & 2002 & Artigo & Português & Média & Baixa & Baixa & Baixa \\
\hline Jorge & 2002 & Dissertação & Português & Alta & Média & Média & Média \\
\hline Lisboa & 2003 & Artigo & Português & Média & Baixa & Baixa & Baixa \\
\hline Stamm & 2003 & Tese & Português & Alta & Alta & Alta & Alta \\
\hline Kaefer & 2003 & Dissertação & Português & Alta & Alta & Alta & Alta \\
\hline Silva & 2004 & Tese & Português & $\overline{\text { Alta }}$ & $\overline{\text { Alta }}$ & Alta & Alta \\
\hline $\begin{array}{l}\text { Costa, } \\
\text { Chaves e } \\
\text { Oliveira }\end{array}$ & 2005 & Artigo & Português & Média & Baixa & Baixa & Baixa \\
\hline Caldas & 2006 & Dissertação & Português & Alta & Alta & Alta & Alta \\
\hline Ogola & 2007 & Artigo & Inglês & Alta & Alta & Alta & Alta \\
\hline $\begin{array}{c}\text { Abi- } \\
\text { Chahin, } \\
\text { Almeida e } \\
\text { Lins }\end{array}$ & 2008 & Artigo & Português & Média & Alta & Alta & Alta \\
\hline $\begin{array}{c}\text { Omena e } \\
\text { Santos }\end{array}$ & 2008 & Artigo & Português & Média & Média & Média & Média \\
\hline $\begin{array}{l}\text { Oliveira e } \\
\text { Moura }\end{array}$ & 2009 & Artigo & Português & Alta & Alta & Alta & Alta \\
\hline Simonetti & 2010 & Monografia & Português & Alta & Média & Média & Média \\
\hline Santos & 2010 & Monografia & Português & Média & Alta & Alta & Alta \\
\hline Finucci & 2010 & Dissertação & Português & Alta & Alta & Alta & Alta \\
\hline Medeiros & 2010 & Dissertação & Português & Alta & Alta & Alta & Alta \\
\hline $\begin{array}{c}\text { Magalhães, } \\
\text { Martins e } \\
\text { Santos }\end{array}$ & 2011 & Artigo & Português & Média & Alta & Alta & Alta \\
\hline Sanches & 2011 & Dissertação & Português & Alta & Alta & Alta & Alta \\
\hline $\begin{array}{l}\text { Silva e } \\
\text { Silva }\end{array}$ & 2013 & Artigo & Português & Alta & Baixa & Baixa & Baixa \\
\hline $\begin{array}{c}\text { Brito, } \\
\text { Vasconcello } \\
\text { s e Oliveira }\end{array}$ & 2013 & Artigo & Português & Média & Alta & Alta & Alta \\
\hline Bastos & 2013 & Dissertação & Português & Média & Baixa & Baixa & Baixa \\
\hline $\begin{array}{l}\text { Cremonez } \\
\text { et al. }\end{array}$ & 2014 & Artigo & Português & Alta & Alta & Alta & Alta \\
\hline Silva & 2015 & Artigo & Português & Média & Baixa & Baixa & Baixa \\
\hline $\begin{array}{l}\text { Moraes e } \\
\text { D'Aquino }\end{array}$ & 2016 & Artigo & Português & Média & Baixa & Baixa & Baixa \\
\hline
\end{tabular}


MARTINS, THAMIRES; CARMO JUNIOR, GERSINA; Avaliação de Impacto Ambiental: Uma Revisão Sistemática sob a Ótica Metodológica.E\&SEngineeringand Science, (2018), 7:2.

Quadro 1 - Estudos pré-selecionados e critérios de pós-avaliação da qualidade

\begin{tabular}{c|c|c|c|c|c|c|c}
\multicolumn{6}{c}{ Quadro 1 - Estudos pré-selecionados e critérios de pós-avaliação da qualidade } & \multicolumn{2}{c|}{ continuação } \\
\hline Referência & Ano & Tipo & Idioma & \multicolumn{3}{|c|}{ Pré-Avaliação } & $\begin{array}{c}\text { Pós- } \\
\text { Avaliação }\end{array}$ \\
\hline $\begin{array}{c}\text { Almeida; } \\
\text { Garrido; } \\
\text { Almeida }\end{array}$ & 2017 & Artigo & Português & Alta & Alta & Alta & Alta \\
\hline
\end{tabular}

Fonte: Autoria própria.

Dentre os artigos que obtiveram ponderação alta, onze abordavam sobre as metodologias usuais empregadas em avaliações de impactos ambientais, sendo eles: STAMM, 2003; KAEFER, 2003; SILVA, 2004; CALDAS, 2006; OGOLA, 2007; OLIVEIRA; MOURA, 2009; FINUCCI, 2010; MEDEIROS, 2010; SANCHES, 2011; CREMONEZ ET AL., 2014; ALMEIDA; GARRIDO; ALMEIDA, 2017. Dentre as metodologias retratadas por estes autores, seis destas foram exibidas com maior recorrência: Ad Hoc espontâneo, Listas de controle (Checklist), Matrizes de interação, Redes de interação, Superposição de mapas (Overlay Mapping) e Modelos de simulação.

O método Ad Hoc se fundamenta no conhecimento empírico de especialistas do assunto e/ou da área em questão. Os impactos elencados por este método são identificados, de forma habitual, por meio de brainstorming, descrevendo-os e sintetizando-os em seguida através de tabelas ou matrizes (SILVA, 2004; CALDAS, 2006; OLIVEIRA; MOURA, 2009; CREMONEZ et al., 2014). A bibliografia retrata, como um dos exemplos mais populares do método Ad Hoc, o método Delphi (ou Delfos). Neste método são utilizadas várias rodadas com questionários nos quais os especialistas elucidam suas impressões acerca dos assuntos levantados previamente, até alcançarem consenso ou não. Com a sucessão de rodadas de questionários, os especialistas passam a tomar conhecimento dos pareceres do grupo. Os pontos onde não existe consenso são tabelados como tais (STAMM, 2003).

De acordo com Silva (2004), a metodologia de listagem foi o primeiro método adotado para avaliar os impactos ambientais. Esta metodologia, comumente chamada de checklist ou listas de controle/verificação, refere-se simplesmente à elaboração de uma lista de impactos ambientais, que podem estar desmembrados por fase do empreendimento e por meio afetado, seja ele físico, biológico ou socioeconômico (OGOLA, 2007; OLIVEIRA; MOURA, 2009; ALMEIDA; GARRIDO; ALMEIDA, 2017). Salienta-se que este método possui algumas variações, tais como: listas simples, listas descritivas, listas comparativas, listagens de controle escalar, listagem de controle ponderáveis e questionários (STAMM, 2003; FINUCCI, 2010; SANCHES, 2011).

As matrizes de interação são amplamente utilizadas na etapa de identificação dos impactos do Estudo de Impacto Ambiental (EIA). Este método consiste em técnicas bidimensionais que relacionam ações com fatores ambientais, e é uma das ferramentas de avaliação de impactos ambientais mais utilizadas (CANTER; SADLER, 1997; OLIVEIRA; OGOLA, 2007; MOURA, 2009; MEDEIROS, 2010). Existem inúmeros tipos matrizes, sendo a Matriz de Leopoldo a mais difundida. Esta matriz se baseia em uma lista de 100 ações que podem resultar em impactos ambientais e 88 características ambientais. Esta combinação origina uma matriz com 8.800 casos. A priori, deve-se assinalar todas as possíveis interações entre as ações e os fatores, para a posteriori, estabelecer em uma escala que varia entre 1 e 10 a magnitude e a importância referente a cada impacto, discernindo se o mesmo é positivo ou negativo (OLIVEIRA; MOURA, 2009; FINUCCI, 2010; CREMONEZ et al., 2014).

As redes de interação (ou network, que corresponde ao termo em inglês amplamente difundido pelos especialistas da área para abordar sobre as redes de interação), estabelecem as relações do tipo causa-condições-efeito, possibilitando ser incorporados parâmetros de valor 
em magnitude, importância e probabilidade, permitindo desde o primeiro impacto constatado, delinear o conjunto de ações que podem desencadeá-los de forma direta ou indireta (KAEFER, 2003; OGOLA, 2007; MEDEIROS, 2010; FINUCCI, 2010; SANCHES, 2011). A rede de interação mais difundida é a de Sorensen, que se baseia no reconhecimento da cadeia de impactos indiretos resultantes das condições iniciais, obtidos a partir de matrizes que devem proceder a sua aplicação (CALDAS, 2006).

O método de superposição de mapas consiste na montagem de uma sequência de mapas temáticos, sendo que em um destes há uma indicação de uma característica cultural, social e física que refletem um impacto. Esses mapas quando assimilados, resultam na síntese do panorama ambiental de uma determinada área geográfica, podendo ser realizados conforme os conceitos de vulnerabilidade ou potencial dos recursos ambientais. Nestes mapas, a intensidade das cores corresponde às áreas com impactos ambientais mais intensos (CANTER; SADLER, 1997; OLIVEIRA; MOURA, 2009; CREMONEZ et al., 2014; ALMEIDA; GARRIDO; ALMEIDA, 2017). Atualmente, com o auxílio de satélites e computação gráfica, a aplicação deste método vem adquirindo maior simplicidade, rapidez e precisão quando comparado aos métodos citados anteriormente (STAMM, 2003).

Os modelos de simulação correspondem à modelos matemáticos que tem por finalidade representar, da forma mais próxima à realidade, a estrutura e o funcionamento dos sistemas ambientais, explorando de forma enfática seus fatores físicos, biológicos e socioeconômicos. Estes modelos são estruturados com base na definição de objetivos, seleção de variáveis, identificação das suas inter-relações, discussão e interpretação dos resultados. É um método de grande aplicação em projetos de usos múltiplos e permite ser empregado mesmo após o início das operações de um projeto (SILVA, 2004; CALDAS, 2006; CREMONEZ et al., 2014).

Quadro apresenta quais foram as potencialidades e limitações referentes às metodologias elucidadas anteriormente.

Quadro 2 - Potencialidades e limitações referentes aos métodos de AIA identificados na revisão sistemática

\begin{tabular}{|c|c|c|}
\hline Método & Potencialidades & Limitações \\
\hline $\begin{array}{c}\text { Ad Hoc } \\
\text { espontâneo }\end{array}$ & $\begin{array}{c}\text { Forma simples e compreensiva, permite } \\
\text { o envolvimento direto dos interessados; } \\
\text { Adequado para casos de escassez de } \\
\text { dados; Fornece orientações para outras } \\
\text { avaliações; Rapidez na identificação dos } \\
\text { impactos; Fácil compreensão; Baixo } \\
\text { custo. }\end{array}$ & $\begin{array}{l}\text { Limitação para examinar o impacto global } \\
\text { oriundo de todas as variáveis ambientais } \\
\text { envolvidas no processo, devido à sua } \\
\text { avaliação individual dos impactos; Não } \\
\text { permite projeções e previsões, nem a } \\
\text { identificação de impactos de segunda } \\
\text { ordem; Apresenta resultados com alto } \\
\text { grau de subjetividade. }\end{array}$ \\
\hline $\begin{array}{c}\text { Listas de } \\
\text { controle } \\
\text { (Checklist) }\end{array}$ & $\begin{array}{l}\text { Simplicidade na aplicação; Apresenta } \\
\text { formato conciso e organizado; } \\
\text { Adequado para análises preliminares, } \\
\text { indicando a priori os impactos mais } \\
\text { relevantes; Instiga a avaliação das } \\
\text { consequências; Pode, de forma limitada, } \\
\text { incorporar escalas de valoração e } \\
\text { ponderação. }\end{array}$ & $\begin{array}{l}\text { Compartimentação e fragmentação; Não } \\
\text { analisa as interações dos fatores ou dos } \\
\text { impactos ambientais; Não considera a } \\
\text { dinâmica dos sistemas ambientais; A } \\
\text { identificação dos efeitos é qualitativa e } \\
\text { subjetiva; Impossibilidade de identificar } \\
\text { impactos secundários e fazer predições; } \\
\text { Não capta valores e conflitos. }\end{array}$ \\
\hline $\begin{array}{l}\text { Superposi- } \\
\text { ção de } \\
\text { mapas } \\
\text { (Overlay } \\
\text { Mapping) }\end{array}$ & $\begin{array}{l}\text { Permite visualizar relação espacial entre } \\
\text { fatores ambientais e identificação da } \\
\text { extensão dos impactos; Forte poder de } \\
\text { síntese, facilita a comparação com e sem } \\
\text { o projeto; }\end{array}$ & $\begin{array}{l}\text { Subjetividade dos resultados; Dificuldade } \\
\text { na integração dos impactos } \\
\text { socioeconômicos; Desconsidera a } \\
\text { dinâmica dos sistemas ambientais; }\end{array}$ \\
\hline
\end{tabular}


MARTINS, THAMIRES; CARMO JUNIOR, GERSINA; Avaliação de Impacto Ambiental: Uma Revisão Sistemática sob a Ótica Metodológica.E\&SEngineeringand Science, (2018), 7:2.

Quadro 1 - Potencialidades e limitações referentes aos métodos de AIA identificados na revisão sistemática

continuação

\begin{tabular}{|c|c|c|}
\hline Método & Potencialidades & Limitações \\
\hline $\begin{array}{l}\text { Superposi- } \\
\text { ção de } \\
\text { mapas } \\
\text { (Overlay } \\
\text { Mapping) }\end{array}$ & $\begin{array}{l}\text { Útil em grandes projetos e seleção de } \\
\text { alternativas, em diagnósticos ambientais } \\
\text { e análise de potencialidade de regiões; } \\
\text { Método rápido de análise dos impactos. }\end{array}$ & $\begin{array}{l}\text { Uso limitado pela superposição de muitos } \\
\text { mapas; Não admite fatores ambientais que } \\
\text { não possam ser mapeados. }\end{array}$ \\
\hline $\begin{array}{l}\text { Matrizes de } \\
\text { interação }\end{array}$ & $\begin{array}{l}\text { Compreensivo para comunicação de } \\
\text { resultados; Cobre fatores ambientais } \\
\text { naturais e sociais; Acomoda dados } \\
\text { quantitativos e qualitativos; Fornece boa } \\
\text { orientação para prosseguimento dos } \\
\text { estudos; } \\
\text { Introduz multidisciplinaridade; Baixo } \\
\text { custo. }\end{array}$ & $\begin{array}{l}\text { Baixa eficiência na avaliação de impactos } \\
\text { indiretos; Não identifica inter-relações, } \\
\text { podendo haver dupla contagem dos } \\
\text { impactos ou subestimativas dos mesmos; } \\
\text { Compartimenta o meio ambiente; Baseia- } \\
\text { se, principalmente, no meio físico e biótico; } \\
\text { Subjetividade na atribuição da magnitude, } \\
\text { não sendo usado critérios explícitos no } \\
\text { estabelecimento do peso dos impactos; } \\
\text { Índice global de impacto para avaliação } \\
\text { não é pertinente, devido à natureza distinta } \\
\text { dos impactos; Não considera aspectos } \\
\text { temporais e especiais em sua análise; Não } \\
\text { atende às demais etapas do Estudo de } \\
\text { Impacto Ambiental. }\end{array}$ \\
\hline $\begin{array}{l}\text { Redes de } \\
\text { Interação }\end{array}$ & $\begin{array}{l}\text { Fácil compreensão; Permite a } \\
\text { introdução de parâmetros estatísticos; } \\
\text { Trata dados qualitativos e quantitativos; } \\
\text { Visualização entre ação e impacto; } \\
\text { Avaliação de impactos indiretos; } \\
\text { Medidas de mitigação e controle podem } \\
\text { ser visualizadas; Promove a integração } \\
\text { entre impactos de } 1^{\mathrm{a}}, 2^{\mathrm{a}} \text { e } 3^{\mathrm{a}} \text { ordem. }\end{array}$ & $\begin{array}{l}\text { Falhas na detecção de aspectos temporais, } \\
\text { dinâmica do sistema e relevância dos } \\
\text { impactos; Impossibilidade de projeções } \\
\text { futuras; Grandes ações resultam em redes } \\
\text { extensas e sem valor prático; Carência de } \\
\text { informações dificulta aplicação; Risco de } \\
\text { dupla contagem; Não especifica valores; } \\
\text { Índice global pode mascarar incertezas nos } \\
\text { dados internos; Dificuldade na distinção } \\
\text { entre impactos de curto e longo prazo; Não } \\
\text { atende às demais etapas do Estudo de } \\
\text { Impacto Ambiental. }\end{array}$ \\
\hline $\begin{array}{l}\text { Modelos de } \\
\text { simulação }\end{array}$ & $\begin{array}{l}\text { Explora a não-linearidade e ligações } \\
\text { indiretas; Perspectiva temporal; Rapidez } \\
\text { pelo uso decomputadores;Útil para } \\
\text { projeto de usos múltiplos; Ajuda a coleta } \\
\text { e organização dos diferentes tipos de } \\
\text { dados e a identificação de deficiência } \\
\text { desses dados, no estágio inicial do } \\
\text { processo;Possibilidade de utilização } \\
\text { após o início da operação; Considera a } \\
\text { dinâmica dos sistemas ambientais, } \\
\text { interação entre fatores e impactos, e } \\
\text { variável temporal. }\end{array}$ & $\begin{array}{l}\text { Complexidade; Exigência de especialistas } \\
\text { para o desenvolvimento de modelos } \\
\text { matemáticos; Dificuldade em encontrar } \\
\text { dados disponíveis ou de obter dados } \\
\text { confiáveis para a calibração do } \\
\text { modelo;Limite de variáveis; Pressupostos e } \\
\text { estimativas não são } \\
\text { explicitados;Dificuldades de comunicação } \\
\text { podem levar a tomada de decisão } \\
\text { imperfeita; Custo elevado. }\end{array}$ \\
\hline
\end{tabular}

Fonte: Stamm, 2003; Kaefer, 2003; Silva, 2004; Caldas, 2006; Ogola, 2007; Oliveira e Moura, 2009;

Finucci, 2010; Medeiros, 2010; Sanches, 2011; Cremonez et al., 2014; Almeida; Garrido; Almeida, 2017. 
Finucci (2010) em sua dissertação cita sobre uma metodologia de avaliação de impacto ambiental denominada "Diagramas de Fluxo". De acordo com este autor, esta metodologia é empregada em relações de causalidade, geralmente lineares, entre o meio ambiente e ações elencadas. Entre as suas potencialidades se destaca a facilidade de utilização e a possibilidade de levantamento dos impactos indiretos. Em contrapartida, os diagramas de fluxo se limitam ao apontamento de relações de causa-efeito de caráter linear, e também apresenta dificuldade em sua utilização quando se tem muitas ações e impactos envolvidos no processo.

No que tange avaliações de impactos ambientais em empreendimentos rodoviários, apenas quatro trabalhos dentre os elegíveis para esta revisão sistemática retrataram esta realidade: ABI-CHAIN; ALMEIDA; LINS, 2008; SANTOS, 2010; MAGALHÃES; MARTINS; SANTOS,2011 e BRITO; VASCONCELLOS; OLIVEIRA, 2013.

Abi-Chain, Almeida e Lins (2008) realizaram um estudo de caso na rodovia BR317/AC, que liga a cidade de Assis Brasil à cidade de Rio Branco, capital do Acre, e para a identificação dos possíveis impactos ambientais deste empreendimento, os autores optaram pela utilização da metodologia de Matriz de Interação para o desenvolvimento do trabalho. Com esta matriz, foi possível identificar os possíveis impactos do empreendimento na fase de obras com e sem plano de mitigação, os impactos do empreendimento na fase de operação com e sem plano de mitigação, e os impactos decorrentes da não implementação do empreendimento. Com o resultado final da matriz, os autores concluíram que embora a construção da rodovia gere alguns impactos negativos, implementação do plano de mitigação de impactos ambientais será a melhor alternativa no cenário analisado.

Santos (2010) realizou adaptação da Matriz de Leopold para elencar os possíveis impactos ambientais oriundos das obras de duplicação e melhoras da BR-242 localizada no estado do Espírito Santo abrangendo municípios de Viana, Domingos Martins e Marechal Floriano. $\mathrm{O}$ autor demonstrou o elevado nível de impactos significativos com a construção do empreendimento e a inviabilidade ambiental sem a adoção de medidas efetivas para mitigar ou minimizar os impactos adversos. Após a consideração destas medidas elencadas com a matriz, o empreendimento passou a ser viável ambientalmente.

Magalhães, Martins e Santos (2011) em seu estudo buscaram identificar os impactos ambientais relacionados à pavimentação da rodovia MG-307 no município de Grão MogolMG, abordando todas as fases do projeto como implantação, operação e manutenção para propor medidas compensatórias e mitigadoras dos impactos identificados, analisando assim os que alteraram a paisagem e vida local da área do entorno. A metodologia utilizada pelos autores foi a Matriz de Interação, que buscou relacionar as operações/ações do empreendimento com os impactos envolvidos. Desta forma, os impactos foram concatenados ao meio físico, biótico e antrópico de forma a realizar o prognóstico do meio mais afetado pelo empreendimento bem como identificar possíveis sinergismos (considerando os efeitos cumulativos, ou seja, com outros impactos similares incidentes sobre a mesma área, ou que apresentem efeito potencializado pela combinação de impactos entre si), em sua gama de impactos.

Brito, Vasconcellos e Oliveira (2013) realizaram um estudo de caso para avaliar os impactos socioambientais oriundos da construção e reestruturação da Rodovia MG-010 no trecho compreendido entre Hospital Risoleta Tolentino Neves e Viaduto Senhor do Bonfim, e, ainda, analisar as medidas de compensação e mitigação promovidas no trecho. A metodologia adotada pelos autores foi a superposição de mapas através dos softwares Global Mapper e ArcGIS, onde as imagens de satélite foram georreferenciadas e, nelas, inseridas informações cartográficas como base em uma imagem com informação espacial preexistente. Intensificação dos processos erosivos, aumento do tempo de travessia, ausência no gerenciamento dos resíduos líquidos e sólidos e a desconfiguração da paisagem local 
representam alguns dos impactos identificados pela Superposição de mapas (Overlay Mapping) empregada ao longo do trecho estudado na Rodovia MG - 010.

Isto posto, nota-se que a adoção da metodologia de matrizes de interação para a identificação de possíveis impactos ambientais em empreendimentos rodoviários se encontra mais difundida entre as metodologias apresentadas anteriormente. Esse fato deve-se a sua facilidade, baixo custo e capacidade de apresentar os resultados de forma clara e precisa em empreendimentos de grande porte, como os rodoviários, podendo ser caracterizada, desta forma, como uma metodologia satisfatória para a identificação de impactos ambientais em rodovias. Não obstante, o método de superposição de mapas adotado por Brito, Vasconcellos e Oliveira (2013), garante rapidez e eficiência ao processo, devendo ser amplamente estudado neste escopo devido a sua destreza aplicável em projetos de grande porte, favorecendo os diagnósticos ambientais e análise de potencialidade de regiões.

\section{CONCLUSÃO}

A seleção da metodologia a ser utilizada na avaliação dos impactos ambientais consiste em uma tarefa intrínseca de cada caso que se apresenta e deve partir do comparativo entre os métodos de aplicação existentes. Conhecendo-se tais metodologias é possível obter uma avaliação mais confiável e precisa dos impactos acarretados, mitigando aqueles que forem nocivos ao meio ambiente.

A revisão sistemática identificou as metodologias mais usuais para a avaliação de impactos ambientais como sendo: Ad Hoc espontâneo, Listas de controle (Checklist), Matrizes de interação, Redes de Interação, Superposição de mapas (Overlay Mapping) e Modelos de simulação, não descartando outras como os Diagramas de Fluxo. A pesquisa de cada uma das metodologias anteriormente citadas elucida os diferentes graus de subjetividade inerentes em sua aplicação e os possíveis obstáculos de quantificação para cada caso específico. Desta forma, faz-se necessário o estudo aprofundado do empreendimento ao qual se objetiva avaliar, procurar conhecer as ferramentas e informações disponíveis acerca do objeto de estudo, para que possa ser eleito o melhor método para identificar os possíveis impactos ambientais.

Dentre as metodologias usuais encontradas, a Matriz de Interação foi encontrada com maior recorrência na avaliação de impactos referentes aos empreendimentos rodoviários. Esta metodologia é empregada com maior frequência frente às demais em consequência da sua versatilidade e capacidade de se adaptar às demandas do empreendimento. Porém, ressalta-se o baixo número de artigos e/ou produções científicas publicadas acerca das avaliações de impactos de rodovias.

Não obstante, o diálogo existente entre o profissional com formação ambiental e aquele especializado nas técnicas que envolvem o desenvolvimento do empreendimento é fundamental no processo de escolha de método.

\section{REFERÊNCIAS}

ABI-CHAHIM, J. O.; ALMEIDA, J. R.; LINS, G. A. Avaliação de Impactos Ambientais: Estudo de Caso. Coleção Artigos Técnicos: Série Gestão e Planejamento Ambiental, Rio de Janeiro, n. 8, 30 p., 2008.

ALMEIDA, F. S.; GARRIDO, F. S. R. G.; ALMEIDA, Â. A. Avaliação de impactos ambientais: Uma introdução ao tema com ênfase na atuação do gestor ambiental. Diversidade e Gestão, Três Rios, v. 1, n. 1, p.70-87, jul. 2017. 
BASTOS, L. P. Matriz e índice de avaliação de impactos ambientais para a Implantação de pequenas centrais hidrelétricas. 2013. $111 \mathrm{f}$. Dissertação (Mestrado) - Programa de Pósgraduação em Desenvolvimento de Tecnologia, Instituto de Engenharia do Paraná, Curitiba, 2013.

BRASIL. Lei $\mathrm{n}^{\circ}$ 6.803, de 02 de julho de 1980. Dispõe sobre as diretrizes básicas para o zoneamento industrial nas áreas críticas de poluição, e dá outras providências. Diário Oficial [da] República Federativa do Brasil, Brasília, DF, 03 jul.1980.

BRASIL. Lei n ${ }^{\circ}$ 6.938, de 31 de agosto de 1981. Dispõe sobre a Política Nacional do Meio Ambiente, seus fins e mecanismos de formulação e aplicação, e dá outras providencias. Diário Oficial [da] República Federativa do Brasil, Brasília, DF, 02 set.1981.

BRASIL. Conselho Nacional do Meio Ambiente. Resolução n.001, de 23 de janeiro de 1986. Dispõe sobre critérios básicos e diretrizes gerais para o Relatório de Impacto Ambiental RIMA. Diário Oficial [da] República Federativa do Brasil, Brasília, DF, 17 fev. 1986.

BRITO, T. S. A.; VASCONCELlOS, F. C. W.; OLIVEIRA, F. L. P. Avaliação de impactos ambientais na rodovia MG - 010: Estudo de caso no vetor norte de Belo Horizonte (MG). Ciência e Natura, Santa Maria, v. 35, n. 2, p. 206-214, dez. 2013.

CALDAS, F. V. Estudo de impacto ambiental em empreendimentos dutoviários: Análise da elaboração, acompanhamento e monitoramento durante a fase da construção. 2006. $177 \mathrm{f}$. Dissertação (Mestrado) - Programa de Pós-Graduação em Sistemas de Gestão, Universidade Federal Fluminense, Niterói, 2006.

CASTRO, A. A. Revisão Sistemática e Meta-análise. 2001. Disponível em: <http://www.usinadepesquisa.com/metodologia/>. Acesso em: 10 out. 2017.

COSTA, M. V.; CHAVES, P. S. V.; OLIVEIRA, F. C. de. Uso das técnicas de avaliação de impacto ambiental em estudos realizados no Ceará. In: CONGRESSO BRASILEIRO DE CIêNCIAS DA COMUNICAÇÃO, Não use números Romanos ou letras, use somente números Arábicos., 2005, Rio de Janeiro. Anais... . Rio de Janeiro: [s.n], 2005. p. 1 - 8.

CREMONEZ, F. E.; CREMONEZ, P. A.; FEROLDI, M.; CAMARGO, M. P.; KLAJN, F. F.; FEIDEN, A. Avaliação de impacto ambiental: Metodologias aplicadas no Brasil. Revista Monografias Ambientais, [s.1.], v. 13, n. 5, p.3821-3830, 16 nov. 2014. Universidade Federal de Santa Maria.

DRESCH, A.; LACERDA, D. P.; ANTUNES JÚNIOR, J. A. V. Design Science Research: Método de Pesquisa para Avanço da Ciência e Tecnologia. Porto Alegre: Bookman, 2014. $204 p$.

FINUCCI, M. Metodologias utilizadas na avaliação do impacto ambiental para a liberação comercial do plantio de transgênicos: Uma contribuição ao estado da arte do Brasil. 2010. 114 f. Dissertação (Mestrado) - Programa de Pós-graduação em Saúde Pública, Universidade de São Paulo, São Paulo, 2010.

JORGE, A. L. F. A. Avaliação de impactos ambientais na implantação de usinas hidrelétricas no Brasil: estudos de caso. 2002. 149 f. Dissertação (Mestrado) - Programa de Pós-graduação em Administração, Universidade Federal do Rio de Janeiro, Rio de Janeiro, 2002. 
KAEFER, J. E. A avaliação de impactos ambientais em empreendimentos hidrelétricos: Estudo de caso - a usina hidrelétrica de Salto Caxias e seus impactos sobre o município de Boa Vista da Aparecida - PR. 2003. 162 f. Dissertação (Mestrado) - Programa de Pós-graduação em Engenharia de Produção, Universidade Federal de Santa Catarina, Florianópolis, 2003.

LISBOA, M. V. Avaliações ambientais estratégicas de rodovias com a utilização de métodos multicriteriais de auxílio à tomada de decisão. In: Encontro bienal da sociedade brasileira de economia ecológica, 5.,. Caxias do Sul. Publicações do V Encontro Bienal da Sociedade Brasileira de Economia Ecológica. Caxias do Sul, Rio Grande do Sul, 23p. 2003.

MACÊDO, R. M. P. R. de et al. Avaliação de impacto ambiental: um estudo de caso na lavanderia do Hospital Universitário Ana Bezerra - Santa Cruz/RN. In: ENCONTRO NACIONAL DE ENGENHARIA DE PRODUÇÃO, 12, 2002, Curitiba. Anais... . Curitiba: [s.n], 2002.

MAGALHÃES, I. A. L.; MARTINS, R. F.; SANTOS, A. R. Identificação dos impactos ambientais relacionados à pavimentação da rodovia MG 307 no município de Grão Mogol MG. Revista Verde de Agroecologia e Desenvolvimento Sustentável, Mossoró, v. 6, n. 5, p. 10-16, dez. 2011.

MEDEIROS, R. D. Proposta metodológica para avaliação de impacto ambiental aplicada a projetos de usinas de geração eólio-elétricas. 2010. 110 f. Dissertação (Mestrado) Programa de Pós-graduação em Tecnologia Ambiental, Instituto de Pesquisas Tecnológicas do Estado de São Paulo, São Paulo, 2010.

MILARÉ, E. Direito do Ambiente: a gestão ambiental em foco - doutrina, jurisprudência, glossário. 7. ed. São Paulo: Revista dos Tribunais, 2011.

MORAES, C. D.; D’AQUINO, C. A. Avaliação de impacto ambiental: uma revisão da literatura sobre as principais metodologias. In: SIMPÓSIO DE INTEGRAÇÃO CIENTÍFICA E TECNOLÓGICA DO SUL CATARINENSE, 5, 2016, Araranguá. Anais... . Araranguá: [s.n], 2016.

OGOLA, P. F. A. Environmental impact assessment general procedures. In: SHORT COURSE ON SURFACE EXPLORATION FOR GEOTHERMAL RESOURCES, 2., 2007, Naivasha. Anais... . Naivasha: Kenya Electricity Generating Company, 2007. p. 1 - 6. Disponível em: <https://orkustofnun.is/gogn/unu-gtp-sc/UNU-GTP-SC-10-0801.pdf>. Acesso em: 15 out. 2017.

OLIVEIRA, F. C.; MOURA, H. J. T. Uso das metodologias de avaliação de impacto ambiental em estudos realizados no Ceará. Pretexto, Belo Horizonte, v. 10, n. 4, p.79-98, dez. 2009.

OMENA, M. L. R. de A.; SANTOS, E. B. dos. Análise da efetividade da Avaliação de Impactos Ambientais - AIA - da Rodovia SE 100/Sul-Sergipe. Revista Brasileira de Gestão e Desenvolvimento Regional, Taubaté, v. 4, n. 1, p.221-237, 2008.

PIMENTEL, G.; PIRES, S. H. Metodologias de avaliação de impacto ambiental: aplicações e seus limites. Revista Administração Pública, Rio de Janeiro, v. 26, n. 1, p. 56-68, jan./mar. 1992. 
SAMPAIO R. F.; MANCINI M. C. Estudos de revisão sistemática: um guia para síntese criteriosa da evidência científica. Revista Brasileira de Fisioterapia. São Carlos, v. 11, n. 1, p. 83-89, jan./fev. 2007

SANCHES, R. A avaliação de impacto ambiental e as normas de gestão ambiental da série ISO 14000: características técnicas, comparações e subsídios à integração. 2011. 268 f. Dissertação (Mestrado) - Programa de Pós-graduação em Ciências da Engenharia Ambiental, Escola de Engenharia de São Carlos, Universidade de São Paulo, São Carlos, 2011.

SANTOS, H. J. Evolução da avaliação de impacto ambiental para empreendimentos rodoviários: uma análise descritiva e aplicada. 2010. 95 f. Trabalho de conclusão de curso Curso de Engenharia Civil, Faculdade de Engenharia e Arquitetura, Universidade de Passo Fundo, Passo Fundo, 2010.

SANTOS, I. D. C. Avaliação de impacto ambiental e a responsabilidade do Brasil diante da degradação ao meio ambiente. Interfaces Científicas: Direito, Aracajú, v. 1, n. 2, p.67-74, fev. 2013.

SILVA, P. J. Estrutura para identificação e avaliação de impactos ambientais em obras hidroviárias. 2004. 1 v. Tese (Doutorado) - Programa de Pós-graduação em Engenharia Civil, Escola Politécnica, Universidade de São Paulo, São Paulo, 2004.

SILVA, M. P.; SILVA, D. S. da. Avaliação de impactos ambientais em projeto rodoviário urbano: estudo de caso Americana/SP. Revista Ciência e Tecnologia, [s.1], v. 16, n. 28/29, jan. 2013.

SILVA, T. S. da. Métodos de avaliação de impactos ambientais utilizados na revista brasileira de gestão ambiental. Revista Brasileira de Gestão Ambiental, Pombal, v. 9, n. 1, p.9-14, 2015 .

SIMONETTI, H. Estudo de impactos ambientais gerados pelas rodovias: Sistematização do processo de elaboração de EIA/RIMA. 2010. 55 f. TCC (Graduação) - Curso de Engenharia Civil, Universidade Federal do Rio Grande do Sul, Porto Alegre, 2010.

STAMM, H. R. Método para avaliação de impacto ambiental (AIA) em projetos de grande porte: estudo de caso de uma usina termelétrica. 2003. $265 \mathrm{f}$. Tese (Doutorado) Programa de Pós-graduação em Engenharia de Produção, Universidade Federal de Santa Catarina, Florianópolis, 2003. 